OPEN ACCESS

Edited by:

Camilla Anne Hinde,

Wageningen University \&

Research, Netherlands

Reviewed by:

Sheng-Feng Shen,

Academia Sinica, Taiwan

Tom Langen,

Clarkson University, United States

${ }^{*}$ Correspondence:

Gretchen F. Wagner

gretchenwagner3@gmail.com

Specialty section: This article was submitted to

Social Evolution,

a section of the journal

Frontiers in Ecology and Evolution

Received: 19 March 2019 Accepted: 17 September 2019

Published: 22 November 2019

Citation:

Wagner GF, Mourocq E and Griesser M (2019) Distribution of Experimentally Increased Costs of

Parental Care Among Family Members Depends on Duration of Offspring Care in Biparental Birds.

Front. Ecol. Evol. 7:366

doi: $10.3389 /$ fevo.2019.00366

\section{Distribution of Experimentally} Increased Costs of Parental Care Among Family Members Depends on Duration of Offspring Care in Biparental Birds

\author{
Gretchen F. Wagner ${ }^{1,2 *}$, Emeline Mourocq ${ }^{1}$ and Michael Griesser ${ }^{1,3}$ \\ ${ }^{1}$ Department of Anthropology, University of Zürich, Zurich, Switzerland, ${ }^{2}$ Department of Animal Ecology, Netherlands Institute \\ of Ecology (NIOO-KNAW), Wageningen, Netherlands, ${ }^{3}$ Department of Evolutionary Biology and Environmental Studies, \\ University of Zürich, Zurich, Switzerland
}

Biparental care systems are a valuable model to examine conflict, cooperation, and coordination between unrelated individuals, as the interactions between the parents determines their fitness. Temporarily handicapping one parent induces a higher cost of providing care and is a widespread experimental technique for testing coordinated responses to changes in the costs of parental care in birds. However, dissimilarity in experimental designs of handicapping studies has hindered interspecific comparisons of the patterns of cost distribution between parents and their offspring. Here we apply a comparative approach by handicapping a parent at nests of five altricial bird species using the same experimental treatment. Across species, handicapped parents reduced their nest visitation rate, indicating increased costs of parental care for the manipulated parent. Unexpectedly, the partners of handicapped individuals did not compensate for the reduction in care, and the increased costs were subsequently passed to their offspring. The strength of this effect was mediated by the total duration of offspring care; in species with long care periods, the offspring were passed a greater share of the additional cost. This effect was evident in both changes to nest visitation rates and the body mass gain of the nestlings. Surprisingly, these responses were independent of life history pace (i.e., adult survival and fecundity). While most studies of the costs of parental care focus on the trade-off between current and future reproduction or survival (intra-individual trade-offs), our study highlights that a greater attention to inter-generational trade-offs is warranted, particularly in species with prolonged parental care. Moreover, our findings demonstrate that parental care decisions may be weighed more against physiological workload constraints than against future prospects of reproduction, supporting evidence that avian species may devote comparable amounts of energy into survival, regardless of life history pace.

Keywords: parental care, life-history trade-offs, reproductive effort, comparative field study, handicapping experiment 


\section{INTRODUCTION}

Parental care is widespread in animals, but its expression varies greatly among and within species (Cockburn, 2006; Royle et al., 2012) as well as within individuals (Eggers et al., 2008; Ghalambor et al., 2013; Caro et al., 2016). In biparental care systems, the fitness of both parents is jointly affected by the reproductive decisions of each, as well as how they coordinate with each other. Thus, biparental care relies on cooperation between parents to ensure the survival of their offspring, but is also a source of conflict. Both parents face a trade-off between current and future reproduction and should strive to reduce their own effort, in balance with their partner's effort, to ensure that offspring receive enough total care to survive while lessening current costs of parental care for themselves (Trivers, 1972; Drent and Daan, 1980).

A pioneering model suggested that investment in parental care of both parents can be an evolutionary stable strategy (ESS) if one parent reduces its effort, its partner partially compensates and the increased costs are distributed between the partner and the offspring (Houston and Davies, 1985). More recent models have predicted that negotiation between the parents could lead to partial, full or no compensation by partners, depending on the costs and benefits associated with care (Jones et al., 2002; Johnstone and Hinde, 2006). Accordingly, researchers have suggested that parental care effort lies on a "negotiation continuum" (Hinde and Kilner, 2007) within and across species. This continuum is proposed to range from no partner response, where behavioral rules are independent of the behavior and needs of other family members, to highly flexible, where a behavioral change in one family member directly influences the behavior of others. Across species, we expect that this continuum is proximately effected by the immediate demands of reproduction (i.e., needs of the brood) as previously proposed (Johnstone and Hinde, 2006). Ultimately, we expect it to be influenced by the distribution of reproductive effort over an individual's lifespan (i.e., life history pace), as the long-term costs associated with current reproduction vary depending on an individual's future prospects of reproduction (Williams, 1966; Drent and Daan, 1980).

A common experimental technique for testing changes in the costs of parental care is to temporarily handicap one parent, thereby increasing the cost of providing care. In birds, this is often accomplished through the removal of flight feathers. These handicapping experiments have demonstrated large between-species variation in responses to changes in one parent's physical condition, across both parents and their offspring (Table 1). Handicapped birds may maintain or reduce their physical condition and/or their parental effort. Nonexperimental individuals may fully compensate their partner's decrease in care, partially compensate, or copy the behavior of their partner (i.e., decrease care if their partner decreases care). Similarly, the condition of offspring may decline, improve, or stay constant.

Although there have been many experimental manipulations of parental care, to our knowledge only one meta-analysis has previously examined the responses comparatively (Harrison et al., 2009). However, due to variation in the types of manipulation (e.g., clipping feathers vs. adding weight), the behavior examined (e.g., feeding vs. incubation) and the types of responses recorded (e.g., parental behavior vs. parental condition), a thorough examination of the mitigating factors for patterns of parental care across species has not been possible. Indeed, this meta-analysis showed that the type of manipulation played a key role in explaining heterogeneity in parental responses to manipulation of care and that responses differed depending on the behavior being focused on, while species traits that may have accounted for interspecific differences were largely excluded from the analyses.

A drawback of many handicapping studies is that they measure effects on a single trait or individual, by focusing only on the condition or behavioral changes of the handicapped parent, its partner or their offspring (see Table 1). Consequently, it is difficult to determine how experimental effects are distributed between parents and offspring in many cases. Furthermore, the most common measure taken has been changes in the condition of the handicapped individual (Table 1), usually in terms of body mass, which are frequently attributed to an increased reproductive effort. However, these responses may reflect functional corrections to wing loading rather than adverse effects of handicapping (Norberg, 1981; Lind and Jakobsson, 2001), confounding whether there are any changes in reproductive effort. Because changes in the body mass of handicapped birds are difficult to interpret, it is important to measure parental effort directly, via behavioral responses, in combination with the condition of the offspring, so that relative effects can be properly estimated across all of the family members.

Here we handicapped parents in five altricial bird species with biparental care, resulting in one partner facing higher costs of offspring provisioning, which must be paid by the treated bird, its partner, or their offspring. We analyzed the results comparatively to examine differences in parental care behavior of each parent and any effects on nestling condition. Life-history theory predicts that long-lived species should prioritize survival (and thus future reproduction) over current reproduction, and they are consequently expected to be less willing to increase their parental effort compared to short-lived species (Williams, 1966; Drent and Daan, 1980). However, more recent meta-analyses on costs of care suggest that life-history pace may play a smaller role than previously suggested (Santos and Nakagawa, 2012; Elliott et al., 2014). Thus, we expected that responses will vary across the life-history spectrum, but that life history pace alone will not account for interspecific differences.

\section{MATERIALS AND METHODS}

\section{Study Species}

We handicapped individuals of five bird species with biparental care in southern Spain during the breeding seasons of 2013 and 2014 (Table 2). The experiment was conducted in populations of great tits (Parus major), blue tits (Cyanistes caeruleus), and woodchat shrikes (Lanius senator) in the Cordoba region $\left(37^{\circ} 95^{\prime} \mathrm{N}, 4^{\circ} 40^{\prime} \mathrm{W}\right)$, and black wheatears (Oenanthe leucura) and European bee-eaters (Merops apiaster) in the Guadix region 
TABLE 1 | Results from previous studies that increased the costs of parental care through feather removal.

\begin{tabular}{|c|c|c|c|c|c|c|c|}
\hline \multirow[t]{2}{*}{ Common name } & \multirow[t]{2}{*}{ Scientific name } & \multicolumn{3}{|c|}{ Condition } & \multicolumn{2}{|c|}{ Care behavior } & \multirow[t]{2}{*}{ References } \\
\hline & & Focal & Partner & Offspring & Focal & Partner & \\
\hline Blue tit & Cyanistes caeruleus & - & - & $\approx$ & - & $\approx$ & Slagsvold and Lifjeld, 1990 \\
\hline Coal tit & Parus ater & - & & & & & Slagsvold and Lifjeld, 1990 \\
\hline Great tit & Parus major & - & $\approx$ & - & & & Slagsvold and Lifjeld, 1990 \\
\hline Great tit & Parus major & $\approx$ & $\approx$ & $\approx$ & - & + & Sanz et al., 2000 \\
\hline Great tit & Parus major & - & & - & - & & Wegmann et al., 2015 \\
\hline Pied flycatcher & Ficedula hypoleuca & $\approx$ & $\approx$ & - & $\approx$ & $\approx$ & Moreno et al., 1999 \\
\hline Tree swallow & Tachycineta bicolor & & & $\approx$ & $\approx$ & + & Whittingham et al., 1994 \\
\hline Tree swallow & Tachycineta bicolor & - & & & - & & Winkler and Allen, 1995 \\
\hline Common tern & Sterna hirundo & - & & + & & & Nisbet et al., 2004 \\
\hline Black-legged kittiwake & Rissa tridactyla & - & $\approx$ & $\approx$ & $\approx$ & - & Leclaire et al., 2011 \\
\hline Leach's storm-petrel & Oceanodroma leucorhoa & $\approx$ & & - & - & & Mauck and Grubb, 1995 \\
\hline Thin-billed prion & Pachyptila belcheri & - & & $\approx$ & & & Weimerskirch et al., 1995 \\
\hline Cory's shearwater & Calonectris diomedea & $\approx$ & & - & - & & Navarro and González-Solís, 2007 \\
\hline Blue-footed boobie & Sula nebouxii & - & & - & & & Velando, 2002 \\
\hline Blue-footed boobie & Sula nebouxii & $\approx$ & - & - & & & Velando and Alonso-Alvarez, 2003 \\
\hline Cape gannet & Morus capensis & - & $\approx$ & - & - & + & Bijleveld and Mullers, 2009 \\
\hline Little auk & Alle alle & - & - & - & & & Harding et al., 2009 \\
\hline Thick-billed murre & Uria lomvia & $\approx$ & & - & & & Jacobs et al., 2013 \\
\hline
\end{tabular}

+, indicates a significant positive response; -, indicates a significant negative response; $\approx$, indicates no significant response, blanks indicate unmeasured variables.

TABLE 2 | Sample sizes of nests and nestlings for each species included in the experiments.

\begin{tabular}{|c|c|c|c|c|c|}
\hline Common name & Scientific name & \multicolumn{2}{|c|}{ Treatment $n$} & \multicolumn{2}{|c|}{ Control $n$} \\
\hline Black wheatear & Oenanthe leucura & 8 & 28 & 7 & 25 \\
\hline European bee-eater & Merops apiaster & 8 & 39 & 7 & 28 \\
\hline Great tit & Parus major & 7 & 52 & 7 & 51 \\
\hline
\end{tabular}

$\left(37^{\circ} 25^{\prime} \mathrm{N}, 3^{\circ} 05^{\prime} \mathrm{W}\right)$. All nests used in the analyses had two adults, presumably the mother and father, attending to the nestlings. At least one parent was marked for individual identification prior to the experiment, with a combination of plastic colored rings or a temporary mark on their feathers. Because European bee-eaters sometimes have helpers at the nest, both parents were marked early in the nest stages (building or incubating) to reduce the chances of marking a non-breeder, and each nest included in this study was checked for the presence of only two adults attending the nest.

\section{Experimental Design}

This research was conducted in accordance with all applicable laws and rules set forth by the Junta de Andalucía, Spanish Ornithological Society and Bird Migration Centre of Spain, and all necessary permits were in hand when the research was conducted. Experiments were started at each nest based on the developmental stage of the nestlings (as feather growth begins), rather than absolute age, to allow for a better comparison between species with different development schedules. The experimental procedure spanned 5 days. Each nest was recorded with a video camera to obtain the visitation rate for $2-4 \mathrm{~h}$ on the first, second, fourth and fifth days of the experiment. The duration of recording was determined prior to the experiment through observations of each species, and was based on the natural visitation rate to conservatively ensure a minimum of 10 nest visits per observational bout. Recordings were made at the same time of the day for each nest, and nests were assigned to morning, midday, or afternoon recordings using a balanced random design.

On the third day of the experiment, one of the adults at each nest was caught and either handicapped, by removing the 7 and 9th primary feathers on each wing, or was handled (with simulated feather removal) and released as a control. Removal of flight feathers has been demonstrated to increase the energetic demands of flight by increasing wing loading (Pennycuick, 1989; Hedenström and Sunada, 1999), thus increasing the cost of parental care during foraging for provisioning. 


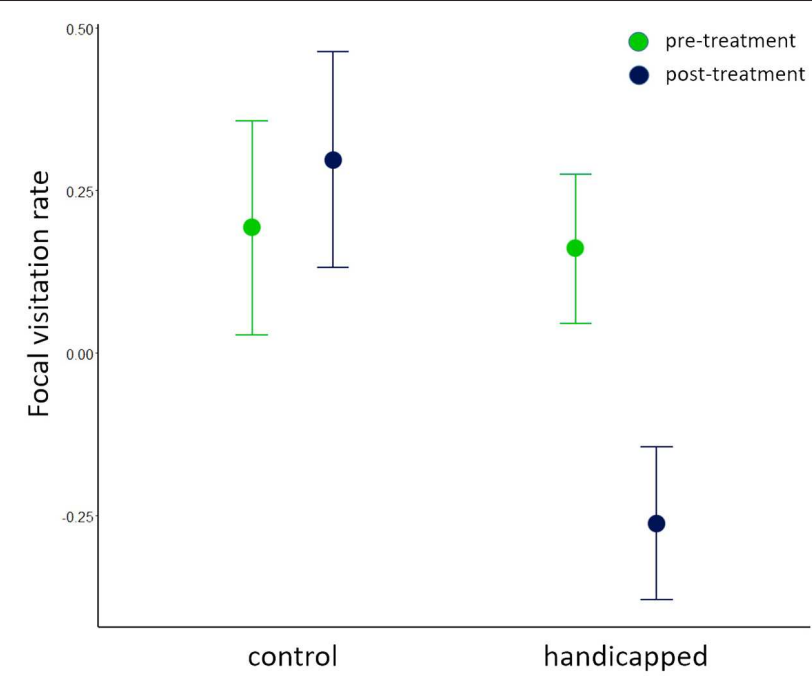

FIGURE 1 | Standardized predicted values ( \pm SE) from mixed model of visitation rates of handicapped and control birds. Prior to the treatment, visitation rates did not differ between the control group and treatment group. After the treatment, handicapped birds reduced their visitation rate.

After recording on the first day, all nestlings were marked for individual identification with a non-toxic permanent marker on one leg. Each nestling was weighed with a digital scale and its wing and tarsus length were measured with dial calipers $(0.1 \mathrm{~mm}$ accuracy) on the first, third and fifth day of the experiment. All nestling measurements within a nest were taken by the same experimenter to maintain consistency across days.

\section{Statistical Analyses}

We predicted that the visitation rates of parents, after handicapping one of them, may be influenced by the adult survival rate, body mass, the body mass-scaled initial reproductive allocation (total mass of eggs produced annually divided by adult body mass, following Sibly et al., 2012), the duration that offspring require provisioning in the nest and after fledging ("care time"), and the duration that offspring stay with their parents subsequent to nutritional independence ("family time," Drobniak et al., 2015). We used a principal component analysis (PCA) to reduce the dimensionality of these predictors, as most of them exhibited moderate to strong correlations (Table S1). Because the units of measurement for traits differed, we relied on the correlation matrix among variables to generate PCA scores rather than the covariance matrix (Graham, 2003). Both the inspection of a Scree plot and Eigenvalues suggested the extraction of two principal components (PCs). To simplify the factor structure by maximizing the variances of loadings and hence facilitate their interpretation, we first performed an oblique (oblimin) rotation of the components, which indicated that the resulting factors were not substantially correlated $(r=0.21)$. We then applied a varimax rotation to the original components. Differences in results of the rotation techniques were negligible, and did not affect the overall pattern of loadings, so we retained the varimax rotation in further analyses (Kieffer, 1998).
The principal components analysis resulted in the extraction of two PC variables (Table S1) that cumulatively explained 79\% of the variance. The first component, hereafter labeled "duration of care," included the care time, body mass, and family time. A high value of this component signifies species with long periods of parental investment. The second component, hereafter labeled "life history pace," included adult survival rate and the index of reproductive allocation (see above). A high value of this component signifies parents with long expected lifespans and low annual reproductive investment.

We fit linear mixed models using a Bayesian framework with Markov chain Monte Carlo (MCMC) methods with the package MCMCglmm (Hadfield, 2010) in R 3.1.0 (R Core Team, 2014) to examine among-species responses to the handicapping procedure. All models were run for 100,000 iterations, with a burn-in phase of 2,000 iterations and a thinning interval of 100 , which resulted in approximately 1,000 samples from the posterior distributions for each model parameter. A reasonably normal distribution of residuals was confirmed for all models. Model convergence was confirmed by visual examination of trace plots and calculation of autocorrelation between iterations. Non-significant interactions $(p>0.05)$ were removed from initial models using a backwards elimination procedure, but non-significant main effects were retained.

\section{Visitation Rates}

Visitation rates were measured as the number of nest visits per hour per nestling. Although we did not confirm that every visit involved food delivery, visitation during the nestling phase is a common proxy for offspring provisioning (Mariette et al., 2011; Mutzel et al., 2013). These rates were averaged for the 2 days prior to catching/handicapping a parent, i.e., "pre-treatment" phase (days 1-2), and the 2 days following catching/handicapping, i.e., "post-treatment" phase (days 4-5). We analyzed sources of variation in visitation rates among the tested species using separate linear mixed-effect models with the total visitation rate at the nest, as well as the visitation rates of each parent, as response variables. Effects in the pretreatment phase and the post-treatment phase were analyzed separately. These models included brood size, duration of care, life history pace, and the two-way interactions between each principal component and treatment as fixed effects, with species as a random factor.

\section{Nestling Growth}

We analyzed sources of variation in nestling growth among all of the tested species using separate linear mixed-effect models of nestling changes in mass, tarsus length, and wing length. Each response variable was measured as the difference in each parameter between the "pre-treatment" phase, and the difference in each measurement of the "post-treatment" phase, and these phases were analyzed separately. Brood size, duration of care, life history pace, treatment, and interactions between treatment and each principal component were included as fixed effects. Random intercepts were specified for species and nest identity. Finally, we analyzed the relationship between nestling growth 


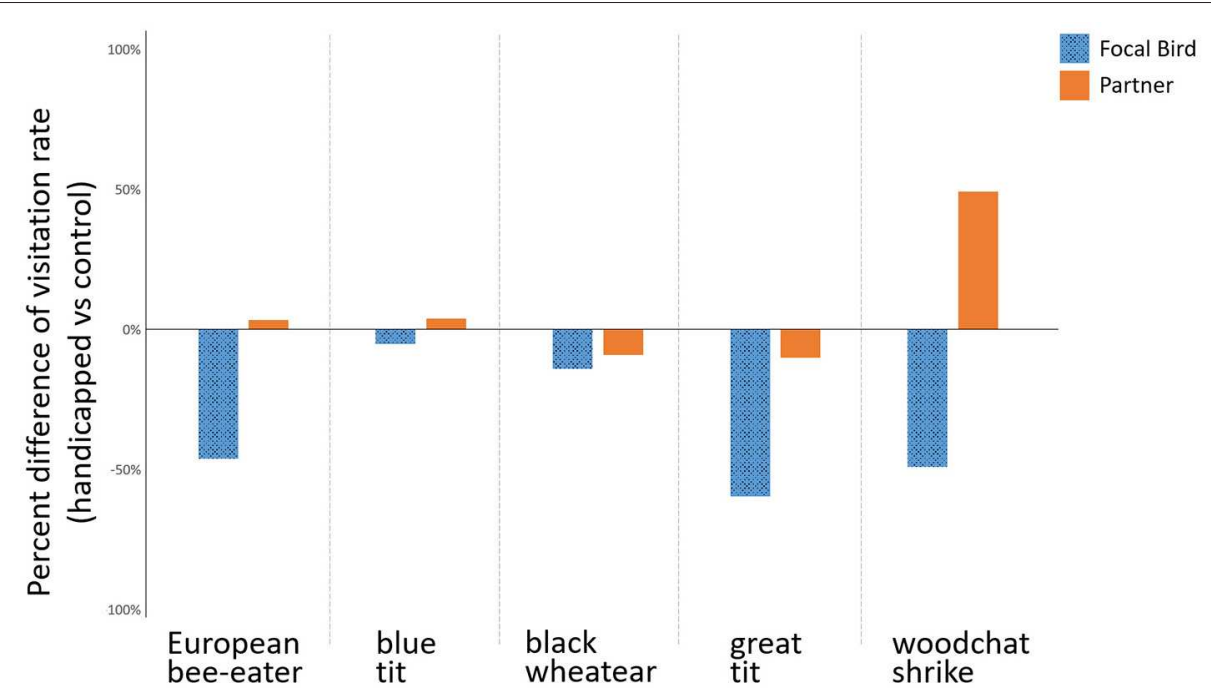

FIGURE 2 | Percent difference between nests with handicapping vs. control treatments in the post-treatment feeding rates of the focal individual and their partners for each species.

FIGURE 3 | Standardized model-predicted total visitation rates varied according to duration of care. (A) Handicapped and control groups had similar visitation rates
during the pre-treatment phase. (B) Total visitation rates were lower in the handicapped group during the post-treatment phase, particularly for species with long
durations of care. Shaded area represents 95\% confidence interval.

and visitation rate, with the change in nestling mass as the response variable and the total visitation rate per hour per nestling as a predictor, with species and nest identity specified as random effects.

\section{RESULTS}

The experiment could not be completed in nests that failed before the end of the experiment $(N=9)$ or because a parent was not caught on Day $3(N=8)$ and these 17 nests were excluded from all analyses. Results of total visitation rates (visits per hour per nestling) are based on 61 nests. In 29 of these nests, we were unable to reliably distinguish the individual parent of some nest visits, so these nests were excluded from analyses of individual visitation rates. Nestling growth results are based on 384 nestlings in 72 nests across the five species.

\section{Visitation Rates}

The total visitation rate and the individual visitation rates of either parent did not differ during the pre-treatment phase between the control and the handicapped groups (Figure 3A, Tables 3a-c). In contrast, the visitation rates in the posttreatment phase were lower in handicapped individuals than control individuals (Figures 1, 2, Table 3b), as were total visitation rates (Table 3a). In addition, duration of care interacted with the treatment for the visitation of focal parents in the post-treatment phase, where handicapped parents in species with long care periods reduced visitation more than those with short care periods (Table 3b). This interaction was also observed for total visitation rates during the post-treatment phase (Figure 3B, Table 3a). Across species, visitation rates did not differ between partners of handicapped and control-caught birds (Figure 2, 
TABLE 3 | Mixed model results of effects on (a) total visitation rate, (b) focal individual visitation rate, and (c) partner visitation rate before and after the handicapping (or control catching) of one parent.

\begin{tabular}{|c|c|c|c|c|c|c|c|c|}
\hline \multirow[b]{2}{*}{ Effects } & \multicolumn{4}{|c|}{ Pre-treatment } & \multicolumn{4}{|c|}{ Post-treatment } \\
\hline & Estimate $(\beta)$ & Lower & Upper & pMCMC & Estimate ( $\beta$ ) & Lower & Upper & рMСмС \\
\hline \multicolumn{9}{|l|}{ (a) Total visitation } \\
\hline \multicolumn{9}{|l|}{ Fixed effects } \\
\hline Intercept & 0.14 & -0.96 & 1.18 & 0.70 & 0.26 & -0.67 & 1.23 & 0.39 \\
\hline Life history pace & 0.60 & -0.21 & 1.69 & 0.13 & 0.19 & -0.39 & 0.66 & 0.41 \\
\hline Brood size & -0.03 & -0.54 & 0.56 & 0.84 & -0.09 & -0.44 & 0.25 & 0.68 \\
\hline Treatment & -0.13 & -0.43 & 0.17 & 0.37 & -0.46 & -0.81 & -0.12 & $<0.01$ \\
\hline Treatment $\times$ duration of care & n.a. & n.a. & n.a. & n.a. & -0.35 & -0.70 & -0.03 & 0.04 \\
\hline \multicolumn{9}{|l|}{ Random effects } \\
\hline Duration of care & 1.01 & 0.00 & 1.88 & 0.04 & 0.95 & 0.56 & 1.32 & $<0.01$ \\
\hline Life history pace & 0.30 & -0.45 & 1.16 & 0.42 & 0.22 & -0.10 & 0.52 & 0.16 \\
\hline Brood size & -0.03 & -0.37 & 0.26 & 0.83 & 0.17 & -0.05 & 0.36 & 0.10 \\
\hline Treatment & -0.27 & -0.60 & 0.06 & 0.12 & -0.58 & -0.97 & -0.18 & $<0.01$ \\
\hline Treatment $\times$ duration of care & n.a. & n.a. & n.a. & n.a. & -0.45 & -0.86 & -0.06 & 0.03 \\
\hline \multicolumn{9}{|l|}{ Random effects } \\
\hline Species & 1.20 & $<0.01$ & 3.88 & & 0.05 & $<0.01$ & 0.12 & \\
\hline \multicolumn{9}{|l|}{ (c) Partner visitation } \\
\hline \multicolumn{9}{|l|}{ Fixed effects } \\
\hline Intercept & -1.33 & -2.67 & 0.22 & 0.09 & -1.57 & -3.20 & -0.08 & 0.08 \\
\hline
\end{tabular}

n.a. denotes a term not included in a model. Significant effects are highlighted in bold.

Table 3c), and no included variable accounted for variation in partner responses.

\section{Nestling Growth}

In the pre-treatment phase, the change in nestling mass was not influenced by any of the explanatory variables (Figure 4A, Table 4a). In the post-treatment phase, the change in body mass of nestlings in the handicapped group decreased, but increased in nestlings of the control group, with an increasing duration of care (Figure 4B). Changes in nestling mass were directly related to total visitation rates at the nest (estimate $=0.241$; lower, upper $95 \% \mathrm{CI}=0.125,0.364 ; p \leq 0.001$; Table S2). Analyses of changes in nestling tarsus and wing growth (Tables $\mathbf{4 b}, \mathbf{c}$ ) indicated no treatment effects on both response variables.

\section{DISCUSSION}

Parental care is costly, and parents of iteroparous species are predicted to strive to minimize the costs that they incur in a current reproductive event to ensure future reproductive events (Williams, 1966; Stearns, 1992; Gross, 2005). Our experiments demonstrate that, across five species, increased costs of parental care generally results in a reduced visitation rate by the handicapped parent, and that offspring were passed on the largest share of the additional cost in species with long offspring care periods. Surprisingly, the partners of handicapped individuals generally did not compensate for the reduction of care and thus, the detrimental effects on the nestlings mainly depended on the strength of the response of the handicapped parent.

Contrary to our expectations, life history pace did not influence interspecific differences in the parental care decisions after handicapping. In birds, large-bodied species with long care periods generally have low adult mortality (Speakman, 2005; Valcu et al., 2014). However, in the set of species that we investigated, these traits were not highly correlated, and thus we were able to tease apart where species lie on the pace-of-life spectrum and the associated trade-off between 


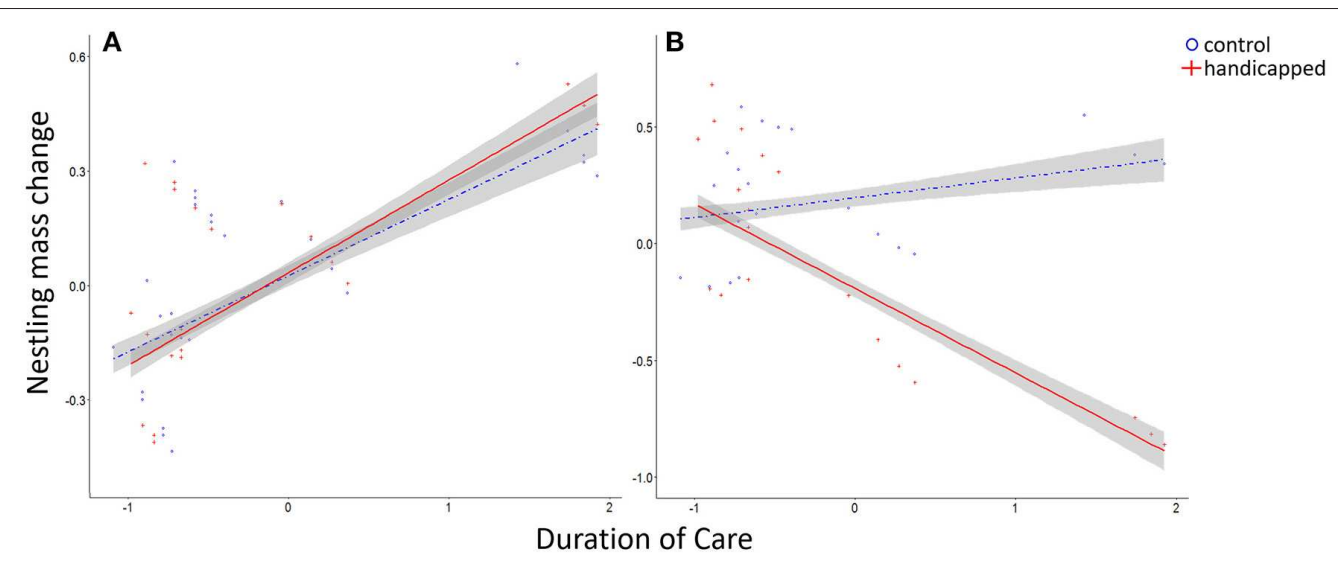

FIGURE 4 | Standardized model-predicted changes in nestling mass varied according to duration of care. (A) The change in nestling mass did not differ between the handicapped and control groups in the pre-treatment phase. (B) In the post-treatment phase, the mass of nestlings in the handicapped group decreased with an increasing duration of care, while the mass of nestlings in the control group increased with the duration of care. Shaded area represents $95 \%$ confidence interval.

TABLE 4 | Mixed model results of effects on nestling (a) mass, (b) tarsus length, and (c) wing length before and after the handicapping (or control catching) of one parent.

\begin{tabular}{|c|c|c|c|c|c|c|c|c|}
\hline \multirow[b]{3}{*}{ Effects } & \multicolumn{4}{|c|}{ Pre-treatment } & \multicolumn{4}{|c|}{ Post-treatment } \\
\hline & \multirow[b]{2}{*}{ Estimate $(\beta)$} & \multicolumn{2}{|c|}{$95 \% \mathrm{Cl}$} & \multirow[b]{2}{*}{ pMCMC } & \multirow[b]{2}{*}{ Estimate $(\beta)$} & \multicolumn{2}{|c|}{$95 \% \mathrm{Cl}$} & \multirow[b]{2}{*}{ рМСмС } \\
\hline & & lower & upper & & & lower & upper & \\
\hline \multicolumn{9}{|l|}{ (a) Mass } \\
\hline \multicolumn{9}{|l|}{ Fixed effects } \\
\hline Intercept & 0.54 & -0.17 & 1.19 & 0.12 & 0.25 & -0.10 & 0.58 & 0.14 \\
\hline Brood size & -0.09 & -0.20 & 0.01 & 0.11 & 0.14 & -0.14 & 0.43 & 0.34 \\
\hline Treatment & 0.00 & -0.31 & 0.30 & 1.00 & -0.39 & -0.84 & 0.01 & 0.07 \\
\hline Treatment $\times$ duration of care & n.a. & n.a. & n.a. & n.a. & -0.42 & -0.85 & 0.02 & 0.04 \\
\hline \multicolumn{9}{|l|}{ Random effects } \\
\hline Species & 0.02 & $<0.01$ & 0.09 & & 0.02 & $<0.01$ & 0.06 & \\
\hline Duration of care & 0.03 & -0.18 & 0.26 & 0.76 & 0.06 & -0.12 & 0.27 & 0.54 \\
\hline Life history pace & -0.05 & -0.43 & 0.36 & 0.78 & 0.04 & -0.31 & 0.41 & 0.83 \\
\hline Brood size & -0.07 & -0.23 & 0.11 & 0.48 & 0.13 & -0.04 & 0.28 & 0.11 \\
\hline Treatment & -0.26 & -0.62 & 0.14 & 0.17 & 0.17 & -0.18 & 0.51 & 0.34 \\
\hline \multicolumn{9}{|l|}{ Random effects } \\
\hline Species & 1.24 & 0.10 & 3.64 & & 0.78 & 0.04 & 2.32 & \\
\hline Nest & 0.58 & 0.37 & 0.82 & & 0.50 & 0.31 & 0.69 & \\
\hline \multicolumn{9}{|l|}{ (c) Wing length } \\
\hline \multicolumn{9}{|l|}{ Fixed effects } \\
\hline Intercept & 0.16 & -1.20 & 1.27 & 0.74 & -0.10 & -0.93 & 0.77 & 0.84 \\
\hline Duration of care & -0.03 & -0.23 & 0.14 & 0.69 & 0.20 & -0.02 & 0.40 & 0.06 \\
\hline
\end{tabular}

n.a. denotes a term not included in a model. Significant effects are highlighted in bold. 
survival and reproduction. Here, the species with the largest opportunity for future reproduction differed from those with the longest burden of parental care. We expected that parents with a slow life history would be most sensitive to costs of reproduction (Williams, 1966; Drent and Daan, 1980; Linden and Møller, 1989). However, only the duration of care but not lifehistory pace predicted whether costs were passed to offspring when faced with an increased cost of care. In accordance with our findings, a meta-analysis that looked explicitly at energy expenditure of handicapped birds found that a species' life history was independent of whether individuals reduced investment into their own energy stores or their offspring's growth (Elliott et al., 2014). Taken together, these results suggest that interspecific differences in reproductive decisions of birds may be largely determined by energetic constraints rather than life history trajectories.

Little is known about the physiological effects of workload during parental care in wild birds (Williams and Fowler, 2015). Previous studies suggest that costs of parental care can be cumulative over a breeding cycle. Many bird species have been shown to rely, at least partially, on nutrient reserves builtup prior to breeding and/or during incubation (Drent and Daan, 1980; Martin, 1987; Moreno, 1989), in preparation for the costly offspring provisioning stage. Thus, the workload during provisioning may be at or even exceed the maximum sustainable workload (Weiner, 1992; Low et al., 2012), and if this is the case over a long period, the risk of mortality is expected to increase (Drent and Daan, 1980). Accordingly, parents are predicted to make decisions about parental care based on maintaining their physical condition above a threshold determined by the trade-off between offspring survival and their expected reproductive value at the end of breeding (Webb et al., 2002). Indeed, theory demonstrates that an increase in the daily energetic costs of care leads to a decrease in the duration of care in birds (Webb et al., 2002), and field data shows that species with long provisioning periods often have a greater loss of body mass than species with short durations of provisioning (Moreno, 1989). Moreover, costs associated with extended parental care have been shown to have important carryover effects. For example, Brent geese (Branta bernicla) that are accompanied by offspring over winter are less likely to breed successfully in the following season (Inger et al., 2010). Taken together, these findings indicate that both the daily energy expenditure and the duration that expenditure, including postfledging care, must be sustained contribute to the overall costs of parental care.

Species with lower baseline costs of parental care may have more leeway to increase their parental investment if necessary, without incurring deleterious consequences, and thus costs allocated to offspring can be minimized in these species. In contrast, species with generally high costs of parental care are more likely to be at their maximum energetic capacity in a given reproductive event, and any increase in the costs associated with caring may have severe consequences in terms of future survival and fitness. Larger species do indeed expend more energy per day toward parental care than small species, however the ratio of energy expenditure to body mass tends to be smaller in large species (Masman et al., 1989). Thus, our results stand in contrast with the prediction that large species expend the smallest share of their energy during parental care (Masman et al., 1989). However, this prediction is based on per-day calculations of energy expenditure relative to energy intake, and does not take into account the duration of care, which is generally longer for large species (Griesser et al., 2017) and thus may accrue higher reproductive costs over the whole breeding cycle.

Given the limited number of samples and species, the interpretation of these findings face limitations. Responses may have varied according to factors we were unable to include due to a lack of statistical power and a lack of variation within the species included here. In particular, the scope of this study did not allow for examination of ecological factors; a species' niche is likely to affect parental care decisions in ways that we were unable to test (Caro et al., 2016). For example, European beeeaters are the only specialized aerial foragers among the species we tested, and consequently handicapped individuals may have accrued higher costs of foraging, particularly because gaps in flight feathers reduce flight maneuverability (Swaddle and Witter, 1997). Moreover, it is possible that parents altered the quality or quantity of the food that they delivered to the nestlings, rather than the number of visits (Wright et al., 1998). Yet, changes in the condition of the nestlings were directly related to the changes to total provisioning rates at the nest, indicating that costs were in fact accrued by nestlings with a handicapped parent. Finally, we were unable to robustly test sex differences in responses due to low and unbalanced samples of one sex in some species. Inspection of the data indicated that both sexes reduced their care when handicapped, but that unmanipulated males may be more likely to compensate for a reduction of care by their partners than unmanipulated females (Figure S1). If so, this may reflect that females are already providing care at their maximum capacity (MacGregor and Cockburn, 2002; Low et al., 2012) and may be more likely to transfer costs of reproduction on to their offspring than males (Santos and Nakagawa, 2012). Nonetheless, the findings of this study give novel empirical insight into different strategies employed across species to deal with increased costs of parental care that should be verified with larger-scale comparative studies. Such studies will be made possible with targeted experimental tests that manipulate parental care in a standardized way, so that comparable effect sizes are obtainable.

To conclude, most studies of the costs of parental care focus on the trade-off between current and future reproduction or survival (intra-individual trade-offs, e.g., Owens and Bennett, 1994; Webb et al., 2002; Alonso-Alvarez and Velando, 2012; Santos and Nakagawa, 2012), while relatively few studies have addressed the fitness consequences of parental decisions on current offspring (intergenerational trade-off, as discussed in Stearns, 1989). Our results suggest that greater attention to inter-generational trade-offs is warranted, particularly in large species with long developmental (and thus parental care) periods. Moreover, our results indicate that, across species, parental care decisions may be weighed more against physiological workload constraints than against future prospects of reproduction, and 
support recent evidence that all bird species may devote comparable amounts of energy into survival, regardless of life history strategy (Santos and Nakagawa, 2012; Elliott et al., 2014).

\section{DATA AVAILABILITY STATEMENT}

A summary data table can be found in the Supplementary Material (Table S3). Detailed raw data will be made available by the authors, without undue reservation, to any qualified researcher.

\section{ETHICS STATEMENT}

This research was conducted in accordance with all applicable laws and rules set forth by the Junta de Andalucia, Spanish Ornithological Society (SEO) and Bird Migration Centre (CMA) of Spain, and all necessary permits were in hand when the research was conducted.

\section{AUTHOR CONTRIBUTIONS}

All authors contributed to study design. GW and EM carried out the field experiments. GW analyzed the data and wrote the first draft of the manuscript. All authors contributed substantially to revisions.

\section{REFERENCES}

Alonso-Alvarez, C., and Velando, A. (2012). Benefits and Costs of Parental Care. The Evolution of Parental Care. Oxford: Oxford University Press, 40-61. doi: 10.1093/acprof:oso/9780199692576.003.0003

Bijleveld, A. I., and Mullers, R. H. (2009). Reproductive effort in biparental care: an experimental study in long-lived Cape gannets. Behav. Ecol. 20, 736-744. doi: 10.1093/beheco/arp054

Caro, S. M., Griffin, A. S., Hinde, C. A., and West, S. A. (2016). Unpredictable environments lead to the evolution of parental neglect in birds. Nat. Commun. 7:10985. doi: 10.1038/ncomms10985

Cockburn, A. (2006). Prevalence of different modes of parental care in birds. Proc. R. Soc. B Biol. Sci. 273, 1375-1383. doi: 10.1098/rspb.2005.3458

Drent, R., and Daan, S. (1980). The prudent parent: energetic adjustments in avian breeding 1). Ardea 68, 225-252. doi: 10.5253/arde.v68.p225

Drobniak, S. M., Wagner, G., Mourocq, E., and Griesser, M. (2015). Family living: an overlooked but pivotal social system to understand the evolution of cooperative breeding. Behav. Ecol. 26, 805-811. doi: 10.1093/beheco/arv015

Eggers, S., Griesser, M., and Ekman, J. (2008). Predator-induced reductions in nest visitation rates are modified by forest cover and food availability. Behav. Ecol. 19, 1056-1062. doi: 10.1093/beheco/arn063

Elliott, K. H., Vaillant, M., Kato, A., Gaston, A. J., Ropert-Coudert, Y., Hare, J. F., et al. (2014). Age-related variation in energy expenditure in a long-lived bird within the envelope of an energy ceiling. J. Anim. Ecol. 83, 136-146. doi: 10.1111/1365-2656.12126

Ghalambor, C. K., Peluc, S. I., and Martin, T. E. (2013). Plasticity of parental care under the risk of predation: how much should parents reduce care? Biol. Lett. 9:20130154. doi: 10.1098/rsbl.2013.0154

Graham, M. H. (2003). Confronting multicollinearity in ecological multiple regression. Ecology 84, 2809-2815. doi: 10.1890/02-3114

Griesser, M., Drobniak, S. M., Nakagawa, S., and Botero, C. A. (2017). Family living sets the stage for cooperative breeding and ecological resilience in birds. PLoS Biol. 15:e2000483. doi: 10.1371/journal.pbio.2000483

\section{FUNDING}

Funding for this study was provided to GW by the Georges and Antoine Claraz Stiftung and to MG by the Swiss National Research Foundation (grant numbers PPOOP3_123520 and PPOOP3_150752).

\section{ACKNOWLEDGMENTS}

We thank Álvaro de las Heras Pardo and Carlota Gutiérrez Arce for their invaluable help both in and out of the field; Francisco Espinosa Alemany, Liliana Ferreira Borges, Emma NorthcoteSmith, Katie Merewether, John Kronenberger, Victor Jiménez García, Matteo Belpinati, Juan Naredo Turrado, Frederico Leite, Daniel Colette, Hailey Scofield, and Filipe Cunha for assistance in the field; Yang Liu, Mengjie Jin, Kai Chen, Yicong Yang, Qiongsi Zhang, and Yi Lin for their contribution to video analyses; Szymon Drobniak and Erik Willems for helpful statistical advice; and Sheng-Feng Shen and Tom Langen for helpful comments on the manuscript.

\section{SUPPLEMENTARY MATERIAL}

The Supplementary Material for this article can be found online at: https://www.frontiersin.org/articles/10.3389/fevo. 2019.00366/full\#supplementary-material

Gross, M. R. (2005). The evolution of parental care. Q. Rev. Biol. 80, 37-45. doi: $10.1086 / 431023$

Hadfield, J. D. (2010). MCMC methods for multi-response generalized linear mixed models: the MCMCglmm R package. J. Stat. Softw. 33, 1-22. doi: $10.18637 /$ jss.v033.i02

Harding, A., Kitaysky, A. S., Hall, M. E., Welcker, J., Karnovsky, N. J., Talbot, S. L., et al. (2009). Flexibility in the parental effort of an Arcticbreeding seabird. Funct. Ecol. 23, 348-358. doi: 10.1111/j.1365-2435.2008.0 1488.x

Harrison, F., Barta, Z., Cuthill, I., and Szekely, T. (2009). How is sexual conflict over parental care resolved? A meta-analysis. J. Evolut. Biol. 22, 1800-1812. doi: 10.1111/j.1420-9101.2009. 01792.x

Hedenström, A., and Sunada, S. (1999). On the aerodynamics of moult gaps in birds. J. Exp. Biol. 202, 67-76.

Hinde, C. A., and Kilner, R. M. (2007). Negotiations within the family over the supply of parental care. Proc. R. Soc. B Biol. Sci. 274, 53-60. doi: 10.1098/rspb.2006.3692

Houston, A. I., and Davies. N. B. (1985). "The evolution of cooperation and life history in the Dunnock, Prunella modularis," in Behavioural Ecology: The Ecological Consequences of Adaptive Behaviour, eds R. M. Sibly and R. H. Smith (Oxford: Blackwell Scientific Publications), 471-487.

Inger, R., Harrison, X. A., Ruxton, G. D., Newton, J., Colhoun, K., Gudmundsson, G. A., et al. (2010). Carry-over effects reveal reproductive costs in a long-distance migrant. J. Anim. Ecol. 79, 974-982. doi: 10.1111/j.1365-2656.2010.01712.x

Jacobs, S. R., Elliott, K. H., and Gaston, A. J. (2013). Parents are a drag: longlived birds share the cost of increased foraging effort with their offspring, but males pass on more of the costs than females. PLoS ONE 8:e54594. doi: 10.1371/journal.pone.0054594

Johnstone, R. A., and Hinde, C. A. (2006). Negotiation over offspring carehow should parents respond to each other's efforts? Behav. Ecol. 17, 818-827. doi: 10.1093/beheco/arl009 
Jones, K. M., Ruxton, G. D., and Monaghan, P. (2002). Model parents: is full compensation for reduced partner nest attendance compatible with stable biparental care? Behav. Ecol. 13, 838-843. doi: 10.1093/beheco/13.6.838

Kieffer, K. M. (1998). "Orthogonal versus oblique rotation: a review of the literature regarding the pros and cons," in Paper Presented at the Annual Meeting of the Mid-South Educational Research Association (New Orleans, LA).

Leclaire, S., Bourret, V., Wagner, R. H., Hatch, S. A., Helfenstein, F., Chastel, O., et al. (2011). Behavioral and physiological responses to male handicap in chick-rearing black-legged kittiwakes. Behav. Ecol. 22, 1156-1165. doi: 10.1093/beheco/arr149

Lind, J., and Jakobsson, S. (2001). Body building and concurrent mass loss: flight adaptations in tree sparrows. Proc. R. Soc. Lond. B Biol. Sci. 268, 1915-1919. doi: $10.1098 / \mathrm{rspb} .2001 .1740$

Linden, M., and Møller, A. P. (1989). Cost of reproduction and covariation of life history traits in birds. Trends Ecol. Evol. 4, 367-371. doi: 10.1016/0169-5347(89)90101-8

Low, M., Makan, T., and Castro, I. (2012). Food availability and offspring demand influence sex-specific patterns and repeatability of parental provisioning. Behav. Ecol. 23, 25-34. doi: 10.1093/beheco/arr145

MacGregor, N. A., and Cockburn, A. (2002). Sex differences in parental response to begging nestlings in superb fairy-wrens. Anim. Behav. 63, 923-932. doi: 10.1006/anbe.2001.1991

Mariette, M. M., Pariser, E. C., Gilby, A. J., Magrath, M. J., Pryke, S. R., and Griffith, S. C. (2011). Using an electronic monitoring system to link offspring provisioning and foraging behavior of a wild passerine. Auk 128, 26-35. doi: 10.1525 /auk.2011.10117

Martin, T. E. (1987). Food as a limit on breeding birds: a life-history perspective. Annu. Rev. Ecol. Syst. 18, 453-487. doi: 10.1146/annurev.es.18.110187.002321

Masman, D., Dijkstra, C., Daan, S., and Bult, A. (1989). Energetic limitation of avian parental effort: field experiments in the kestrel (Falco tinnunculus). J. Evol. Biol. 2, 435-455. doi: 10.1046/j.1420-9101.1989.2060435.x

Mauck, R., and Grubb, T, Jr. (1995). Petrel parents shunt all experimentally increased reproductive costs to their offspring. Anim. Behav. 49, 999-1008. doi: 10.1006/anbe.1995.0129

Moreno, J. (1989). Strategies of mass change in breeding birds. Biol. J. Linn. Soc. 37, 297-310. doi: 10.1111/j.1095-8312.1989.tb01907.x

Moreno, J., Merino, S., Potti, J., De Leon, A., and Rodríguez, R. (1999). Maternal energy expenditure does not change with flight costs or food availability in the pied flycatcher (Ficedula hypoleuca): costs and benefits for nestlings. Behav. Ecol. Sociobiol. 46, 244-251. doi: 10.1007/s002650050616

Mutzel, A., Blom, M. P., Spagopoulou, F., Wright, J., Dingemanse, N. J., and Kempenaers, B. (2013). Temporal trade-offs between nestling provisioning and defence against nest predators in blue tits. Anim. Behav. 85, 1459-1469. doi: 10.1016/j.anbehav.2013.03.043

Navarro, J., and González-Solís, J. (2007). Experimental increase of flying costs in a pelagic seabird: effects on foraging strategies, nutritional state and chick condition. Oecologia 151, 150-160. doi: 10.1007/s00442-006-0559-0

Nisbet, I. C., Arnold, J. M., Galbraith, H., and Hatch, J. J. (2004). Responses of known-aged common terns to experimental shortening of the wings. Waterbirds 27, 13-20. doi: 10.1675/1524-4695(2004)027[0013:ROKCTT]2.0. $\mathrm{CO} ; 2$

Norberg, R. A. (1981). Temporary weight decrease in breeding birds may result in more fledged young. Am. Nat. 118, 838-850. doi: 10.1086/283874

Owens, I. P., and Bennett, P. M. (1994). Mortality costs of parental care and sexual dimorphism in birds. Proc. R. Soc. Lond. B Biol. Sci. 257, 1-8. doi: $10.1098 /$ rspb.1994.0086

Pennycuick, C. J. (1989). Bird Flight Performance. Oxford: Oxford University Press.

R Core Team (2014). R: A Language and Environment for Statistical Computing. Vienna: R Foundation for Statistical Computing.

Royle, N. J., Smiseth, P. T., and Kölliker, M. (2012). The Evolution of Parental Care. Oxford: Oxford University Press. doi: 10.1093/acprof:oso/9780199692576.001.0001

Santos, E., and Nakagawa, S. (2012). The costs of parental care: a meta-analysis of the trade-off between parental effort and survival in birds. J. Evol. Biol. 25, 1911-1917. doi: 10.1111/j.1420-9101.2012.02569.x

Sanz, J. J., Kranenbarg, S., and Tinbergen, J. M. (2000). Differential response by males and females to manipulation of partner contribution in the great tit (Parus major). J. Anim. Ecol. 69, 74-84. doi: 10.1046/j.1365-2656.2000.00373.x
Sibly, R. M., Witt, C. C., Wright, N. A., Venditti, C., Jetz, W., and Brown, J. H. (2012). Energetics, lifestyle, and reproduction in birds. Proc. Natl. Acad. Sci. U.S.A. 109, 10937-10941. doi: 10.1073/pnas.1206512109

Slagsvold, T., and Lifjeld, J. T. (1990). Influence of male and female quality on clutch size in tits (Parus spp.). Ecology 71, 1258-1266. doi: 10.2307/1938263

Speakman, J. R. (2005). Body size, energy metabolism and lifespan. J. Exp. Biol. 208(Pt 9), 1717-1730. doi: 10.1242/jeb.01556

Stearns, S. C. (1989). Trade-offs in life-history evolution. Funct. Ecol. 3, 259-268. doi: $10.2307 / 2389364$

Stearns, S. C. (1992). The Evolution of Life Histories. Oxford: Oxford University Press.

Swaddle, J. P., and Witter, M. S. (1997). The effects of molt on the flight performance, body mass, and behavior of European starlings (Sturnus vulgaris): an experimental approach. Can. J. Zool. 75, 1135-1146. doi: 10.1139/z97-136

Trivers, R. (1972). "Parental investment and sexual selection," in Sexual Selection \& the Descent of Man (New York, NY: Aldine de Gruyter), 136-179. doi: 10.4324/9781315129266-7

Valcu, M., Dale, J., Griesser, M., Nakagawa, S., and Kempenaers, B. (2014). Global gradients of avian longevity support the classic evolutionary theory of ageing. Ecography 37, 930-938. doi: 10.1111/ecog.00929

Velando, A. (2002). Experimental manipulation of maternal effort produces differential effects in sons and daughters: implications for adaptive sex ratios in the blue-footed booby. Behav. Ecol. 13, 443-449. doi: 10.1093/beheco/13.4.443

Velando, A., and Alonso-Alvarez, C. (2003). Differential body condition regulation by males and females in response to experimental manipulations of brood size and parental effort in the blue-footed booby. J. Anim. Ecol. 72, 846-856. doi: 10.1046/j.1365-2656.2003.00756.x

Webb, J. N., Székely, T., Houston, A. I., and McNamara, J. M. (2002). A theoretical analysis of the energetic costs and consequences of parental care decisions. Philos. Trans. R. Soc. Lond. B Biol. Sci. 357, 331-340. doi: 10.1098/rstb.2001.0934

Wegmann, M., Voegeli, B., and Richner, H. (2015). Oxidative status and reproductive effort of great tits in a handicapping experiment. Behav. Ecol. 26, 747-754. doi: 10.1093/beheco/arv006

Weimerskirch, H., Chastel, O., and Ackermann, L. (1995). Adjustment of parental effort to manipulated foraging ability in a pelagic seabird, the thinbilled prion Pachyptila belcheri. Behav. Ecol. Sociobiol. (Print). 36, 11-16. doi: 10.1007/BF00175723

Weiner, J. (1992). Physiological limits to sustainable energy budgets in birds and mammals: ecological implications. Trends Ecol. Evol. 7, 384-388. doi: 10.1016/0169-5347(92)90009-Z

Whittingham, L. A., Dunn, P. O., and Robertson, R. J. (1994). Female response to reduced male parental care in birds: an experiment in tree swallows. Ethology 96, 260-269. doi: 10.1111/j.1439-0310.1994.tb01014.x

Williams, G. C. (1966). Natural selection costs of reproduction and a refinement of lacks principle. Am. Nat. 100, 687-690. doi: 10.1086/2 82461

Williams, T. D., and Fowler, M. A. (2015). Individual variation in workload during parental care: can we detect a physiological signature of quality or cost of reproduction? J. Ornithol. 156, 441-451. doi: 10.1007/s10336-015-1213-6

Winkler, D. W., and Allen, P. E. (1995). Effects of handicapping on female condition and reproduction in tree swallows (Tachycineta bicolor). Auk $112,737-747$.

Wright, J., Both, C., Cotton, P., and Bryant, D. (1998). Quality vs. quantity: energetic and nutritional trade-offs in parental provisioning strategies. J. Anim. Ecol. 67, 620-634. doi: 10.1046/j.1365-2656.1998.00221.x

Conflict of Interest: The authors declare that the research was conducted in the absence of any commercial or financial relationships that could be construed as a potential conflict of interest.

Copyright (C) 2019 Wagner, Mourocq and Griesser. This is an open-access article distributed under the terms of the Creative Commons Attribution License (CC BY). The use, distribution or reproduction in other forums is permitted, provided the original author(s) and the copyright owner(s) are credited and that the original publication in this journal is cited, in accordance with accepted academic practice. No use, distribution or reproduction is permitted which does not comply with these terms. 